\title{
Book Review: Ethical Standards in Forensic Science
}

\section{By Harold Franck and Darren Franck, CRC Press. 2020. ISBN: $9781138496156 \$ 160.00$ (Print)}

Reviewed by Samantha McCrane, University of Florida, Department of Anthropology.

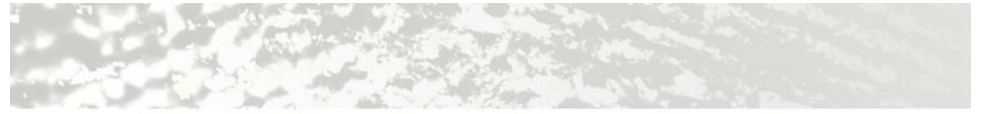

Harold Franck and Darren Franck

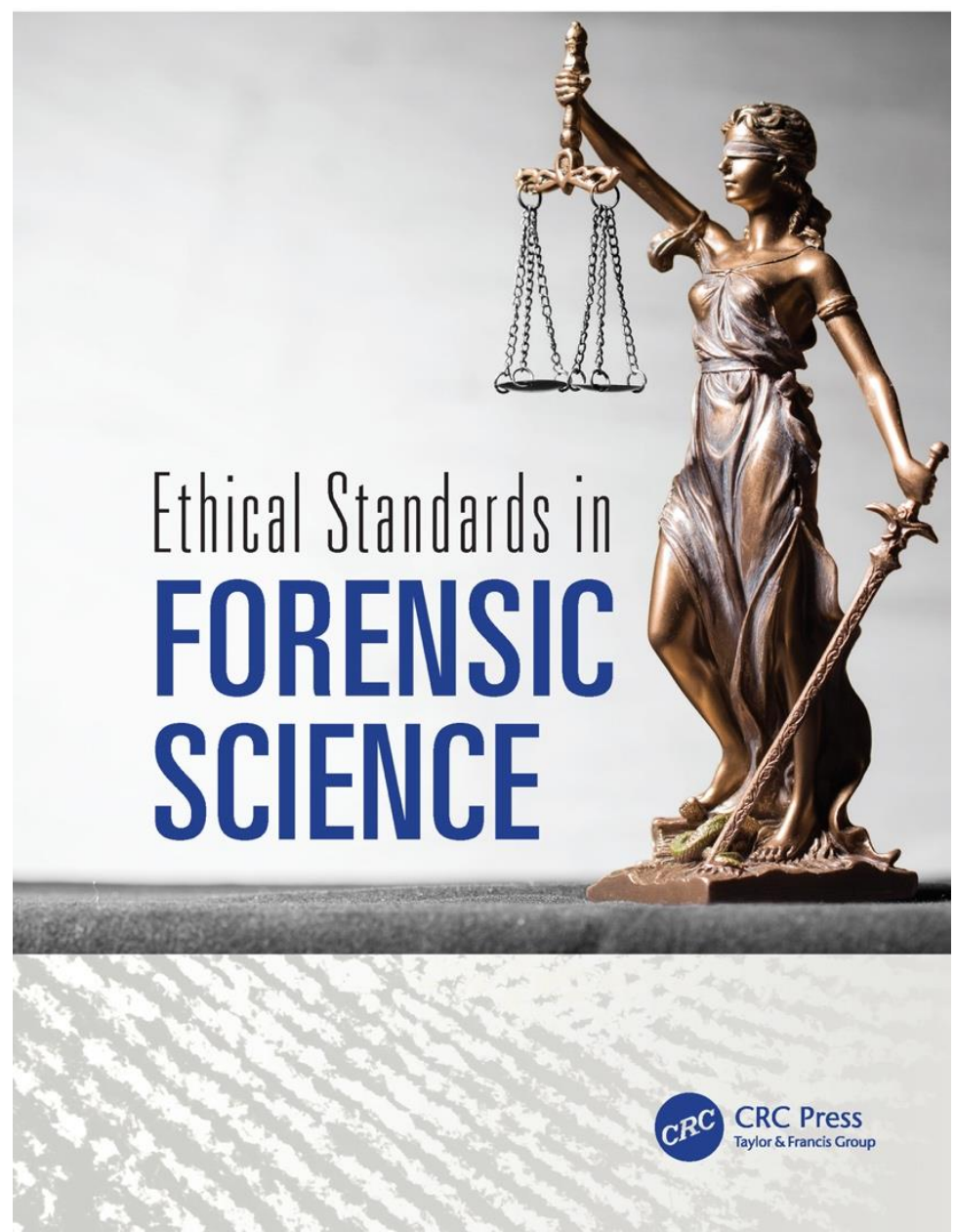

In Ethical Standards in Forensic Science, authors Harold Franck and Darren Franck break down conceptual models of science and incorporate examples from diverse forensic specialties to demonstrate how practices such as cherry picking of data, reliance on unverified assumptions, and trust in expert experience alone have violated ethical obligations among many forensic science practitioners. They address this flagrant neglect of ethics by arguing for the creation of scientific standards that systematize verified, statistically sound forensic methodologies. The book is primarily textual, although the authors do include a few photographs, diagrams, and tables which serve to enhance reader understanding of scenarios discussed. At only 101 pages, including appendices, bibliography, and index, this book is a quick read, but packs a surfeit of topics into that limited space. The authors succinctly cover the history and current state of forensic science, the structure of the United States court system, rules of evidence, findings of the 2009 National Academy of Science (NAS) report, an overview of the scientific method and mathematics, the role of the forensic practitioner, rules governing witness/expert witness testimony, professional standards, bias and error, ethical requirements and deviations, and common misconceptions. In each of the areas covered, the authors demonstrate how adherence to scientific principles is a prerequisite to ethical behavior and provide relevant examples of ethical breaches. In particular, the authors repeatedly return to issues inherent in widely used

McCrane, Samantha (2021) Review of Ethical Standards in Forensic Science, by Harold Franck and Darren Franck. New Florida Journal of Anthropology, 1(2), 8-9 DOI: 
forensic methodologies such as analysis of bite marks, firearms, tire impressions, fingerprints, and burn patterns. In the final (ninth) chapter, "Questionable Science and Common Misconceptions," the authors present original data that directly contradicts existing assumptions on the uniqueness of markings left on cartridges by firing pins- a claim many experts still use to tie specific guns to crimes. Despite the diversity of topics covered in this book, the scope of forensic subfields addressed is somewhat limited. The authors, both of whom are engineers, intentionally exclude chemistry, biology, genetics, and medicine in their discussions. Given their broad examination of science, statistics, and general medico-legal protocols, all of which are applicable to those fields, as well as their overall call for standardization across forensics, an expansion to include some or all of these additional specialties would have been pragmatic. Additionally, while the authors do address the 2009 NAS report and 2016 President's Council of Advisors on Science and Technology (PCAST) report, an elaboration of national reports and commissions established to change and advance forensics in the United States would be desirable (e.g. National Commission on Forensic Sciences, 2017 PCAST Addendum).

The authors state that the intended purpose of this book is to "aid practicing forensic scientists and engineers in their formulation of a proper investigation leading to a report and conclusion which is scientifically valid and acceptable to the court system," ( $p$. $x$ ) however I would argue that this work would be more widely applicable for a collegiate student audience, or even the general public. While the authors' overall message is certainly valuable for practicing forensic scientists, much of the background information included is so basic that practitioners should already be well versed in it. For instance, the authors distinguish between science and art, describe the scientific method, and review foundational statistical concepts like error, sensitivity, and probability. Students would benefit from reviewing these key concepts, as well as the overviews of the judicial system, rules of evidence, and witness testimony. Students also seem to be an ideal audience, as their message of ethical standardization and reform in forensics will likely have higher impact among those minds still being melded before they begin their careers than on seasoned professionals. With the exception of equation derivations, the authors write in an approachable, candid manner that would be both accessible and captivating to a wide range of audiences.

McCrane, Samantha (2021) Review of Ethical Standards in Forensic Science, by Harold Franck and Darren Franck. New Florida Journal of Anthropology, 1(2), 8-9 DOI: 